\title{
Analysis of consumer preferences for information and expert opinion using a discrete choice experiment
}

\author{
Tiago Ribeiro ${ }^{1,2}$ (iD $\cdot$ Armando Corsi $^{3} \cdot$ Larry Lockshin $^{3} \cdot$ Jordan Louviere $^{4}$. \\ Simone Mueller Loose ${ }^{3,5}$
}

Received: 19 September 2017 / Accepted: 14 January 2019 / Published online: 6 February 2019

(c) ISEG - Instituto Superior de Economia e Gestão 2019

\begin{abstract}
We present a study of consumer preferences for information in wine purchases. Consumers are presented with extra information in the form of qualitative product descriptions and quantitative expert ratings. We implement a discrete choice experiment in which we vary experimentally the presence of the descriptions and ratings and the values of the ratings themselves. Respondents are asked to choose amongst a set of 5 wine bottles in a sequence of 21 choice scenarios. We find that the presence of extra information and high expert ratings have a significant impact on the willingness to pay for a given wine. The dispersion of ratings for a given wine does not affect respondents' choices. In our estimates high average ratings by experts carry a premium of AUD \$10.
\end{abstract}

Keywords Stated preference survey - Discrete choice experiments · Experimental design ' Wine preferences - Expert opinion

Tiago Ribeiro

tiago.ribeiro@indera.pt

http://www.indera.pt

Extended author information available on the last page of the article. 